\title{
Sensitive label-free electron chemical capacitive signal transduction for D-dimer electroanalysis
}

\author{
Simone M. Marques ${ }^{\mathrm{a}, 1}$, Adriano Santos ${ }^{\mathrm{a}, 1}$, Luís M. Gonçalves ${ }^{\mathrm{b}, \mathrm{c}, \mathrm{d}}$, João C. Sousa ${ }^{\mathrm{c}, \mathrm{d}}$, \\ Paulo R. Bueno ${ }^{\text {a,* }}$ \\ a Institute of Chemisry, São Paulo State University, Nanobionics Research Group (www.nanobionics.pro.br), Univ. Estadual Paulista, UNESP, Araraquara, São \\ Paulo, Brazil \\ ${ }^{\mathrm{b}}$ Requimte, Departamento de Química e Bioquímica, Faculdade de Ciências, Universidade do Porto, Porto, Portugal \\ ${ }^{\mathrm{c}}$ Life and Health Sciences Research Institute (ICVS), School of Health Sciences, University of Minho, Braga, Portugal \\ 'ICVS/3B's-PT Government Associate Laboratory, Braga/Guimarães, Portugal
}

\section{A R T I C L E I N F O}

\section{Article history:}

Received 2 September 2015

Accepted 30 September 2015

Available online 9 October 2015

\section{Keywords:}

Biosensor

D-dimer

Electroanalysis

Electrochemical Capacitance

Pulmonary embolism

Self-assembled monolayer

\begin{abstract}
A B S T R A C T
D-dimer, an important biomarker in emergency medicine, was determined by applying a label-free electrochemical capacitive approach with an antibody-based selective biosensor consisting of an electroactive self-assembled monolayer mounted on a commercially available gold electrode. Electrochemical measurements were performed by an impedance-derived approach (based on observing the complex capacitance diagrams from where electrochemical capacitance can be obtained as transducer signal) from which it was possible to obtain low limits of detection of $50 \mathrm{fmol} \mathrm{L}^{-1}$ in buffer (PBS) and $7 \mathrm{pmol} \mathrm{L}^{-1}$ in undiluted human serum (performed without any kind of sample pre-treatment), with good coefficient of determination $\left(\mathrm{r}^{2} \geq 0.99\right)$ in a clinically relevant $\mathrm{D}$-dimer concentration range (from 1 to $1,000 \mathrm{ng} \mathrm{mL}^{-1}$ ). These electro analytical/chemistry results pave the way to the creation of lowcost and reliable point-of-care electrochemical approach for the quantitative bedside determination of D-dimer in clinical samples, thus speeding up the diagnosis of potentially lethal, nonetheless treatable, clinical conditions like pulmonary embolism.
\end{abstract}

(c) 2015 Elsevier Ltd. All rights reserved.

\section{Introduction}

D-dimer (DD) is a general term to describe heterogeneous fibrin degradation products present in blood. Circulating DD values are raised in various clinical conditions although, in general, an elevated DD value indicates some type of thrombosis. DD have been used in the past decades to help doctors in the assessment of patients. It has had particular relevance on the management of venous thromboembolism (VTE), particularly pulmonary embolism (PE). PE is a potentially acute life threating pathology of difficult diagnosis [1], and it is still a relevant cause of unexpected in-hospital deaths [2]. Therefore any portable and quick ways of DD determination are welcomed by clinicians and would make it possible to have a result available in emergency medical vehicles, potentially saving lives [3]. Moreover, the clinical application of DD

\footnotetext{
* Corresponding author at: IQ-UNESP, CP 355, CEP 14800-900 Araraquara, São Paulo, Brasil. Tel. +55 1633019642; fax: +55 1633222308.

E-mail address: prbueno@iq.unesp.br (P.R. Bueno).

1 Simone M. Marques and Adriano Santos contributed equally to the development of this manuscript.
}

appears to be spreading to other medical entities beyond PE in the near future [4,5], including terrible events like disseminated intravascular coagulation and aortic aneurism [3], conditions where its early diagnosis and management are absolutely critical for a successful outcome. Furthermore, many studies point to its use as a prognostic indicator as well $[6,7]$.

DD analysis in hospitals laboratories has walked a long path since its introduction in the late 1980s [8]. Initially, DD assays were performed with latex beads coated with anti-DD antibodies and required human visual reading of the agglutination magnitude [9]. Then, by means of several technological advances, automatic Enzyme-Linked Immunosorbent Assays (ELISA) became the most common analytical way of measuring DD [8]. ELISA-based analytical methodologies for DD are indeed quite sensitive and reliable (Limit of detection [10] of $45 \mu \mathrm{g} \mathrm{L}^{-1}$ ), but on the other hand they can be time-consuming and cannot be performed as a bedside assay. Nowadays, the combination of antibody-based sensors (immunosensors) with electrochemical detection has proven to be a successful strategy in the development of a novel generation of DD biosensors [11]. The use of antibodies in biosensors greatly increases their selectivity because they have a specific interaction 
with the aimed analyte, and this biorecognition process has had an impact of utter importance in biosensing applications. Moreover, electrochemical approaches have several advantages over other analytical techniques such as sensitivity, simplicity and the possibility of miniaturization which makes it possible to develop analytical point-of-care devices. Some electroanalytical methodologies for DD determination can be found in literature with low limits of detection (LOD), examples (LODs in parentheses) include approaches designed using cyclic voltammetry $\left(20 \mu \mathrm{gL}^{-1}\right)$ [12], amperometry (25 $\left.\mu \mathrm{g} \mathrm{L}^{-1}\right)$ [13] and impedimetric $\left(0.5 \mu \mathrm{g} \mathrm{L}^{-1}\right)$ [14] immunosensor.

Recently, it has been introduced a new label-free electrochemical approach to detect relevant biomarkers with high sensibility. This approach is based on the use of an electrochemical capacitance signal, referred by us as redox capacitance $\left(C_{r}\right)$ $[15,16]$. Fundamentally the approach is based on the ability of a redox tethered monolayer in store charge when a certain electrical potential is applied. Studies have shown that $C_{r}$ is very sensitive of environmental changes [17] and antibody-antigen coupling $[15,16,18]$, which is ideal for biosensing applications, mainly those related to bedside applications since there is no need of adding any redox probe in solution previously to the electroanalysis, avoiding the introduction of chemical interferences or chemical species on the patient samples.

In terms of transducer signal, electrochemical or redox capacitance, $C_{r}$, is a capacitance related to the faradaic processes operating between the redox active monolayer and the metallic probe (current collector, i.e. the working electrode). In physical chemistry terms $C_{r}$ contains information on both electrostatic and electronic structure contributions for the energy storage process involved with the redox couple contained in the molecular layer self-assembled over the current collector [19]. By using densify functional theory concepts (see support information of reference [19]) it was demonstrated that $C_{r}$ is constituted of a series contribution of electrostatic and quantum capacitive components, i.e.

$\frac{1}{C_{r}}=\frac{1}{C_{e}}+\frac{1}{C_{q}}$

where $C_{e}$ is the electrostatic capacitance and $C_{q}$ is the quantum capacitance, which in its turns, is defined as

$\frac{1}{C_{q}}=\frac{1}{e^{2}}\left[\frac{1}{g_{r}(\mu)}+\frac{1}{g_{l}(\mu)}\right]$ where $g_{r}(\mu)$ and $g_{l}(\mu)$ are density of states functions (right) and (left) [20], respectively, representing the density of states of two different chemical systems when electrons are separated from one to another due to the existence of an externally imposed potential difference, where $\mu=e V$ is the chemical potential of the electrons directly related to the potential difference, but stated in terms of energy per electron. Note that for two metallic probes both density of states [in Eqn. (2)] are huge and so that the contribution of $C_{q}$ to $C_{r}$ [in Eqn. (2)] is null in a way that $C_{r} \sim C_{e}$ and there is obviously no quantum contribution to the electrochemical capacitance.

On the other hand, in the particular situation where one plate is the metallic working electrode with a density of states $g_{l}(\mu)$ and the other "plate" is an electroactive molecular layer self-assembled over the metallic working electrode with a density of states $g_{r}(\mu)$, it is easy to observe that $g_{l}(\mu) \gg g_{r}(\mu)$ and thus Eqn. (2) reduces to $C_{q}=e^{2} g_{r}(\mu)$. Assuming now that the variation of $C_{e}$ with the electrochemical energy $(\mu)$ of the electrode is minimal, thus the redox capacitance is directly proportional to the redox density of state of the molecular redox layer self-assembled over the working electrode and thus

$C_{r} \propto e^{2} g_{r}(\mu)$

Indeed, experimentally $[17,20,21]$ it is observed that $g_{r}(\mu)$ has a Gaussian shape as a function of $\mu$, i.e. as a function of the potential or energy of the working electrode. From an electroanalytical point of view what can be observed is that $C_{r}$ constitutes a very sensible and useful electronic transducer signal [15,16,18,22-24]. The sensitivity is obviously high because it can be sensible to any changes on the electronic structure (consequently sensible to any kind of chemical interaction) of the molecular layer interface, being it electrostatic or yet only based on changes on the electronic states of the attached molecule constituting the receptive interface of a given biosensing device.

Therefore, in terms of biosensing interface, it is possible to design bi-functional molecular layer comprised, for instance, of a self-assembled monolayer (SAM) containing two different thiols (see schematic representation in Fig. 2), i.e. one functioning as electrochemical transduction signal (a redox tethered end group thiol) and another one functioning as the chemical coupling or site of the recognition biological element to detect specific and relevant biomarkers. The impedance signal associated with this molecular engineered interface can be described by an equivalent circuit containing two parallel branches (Fig. 1a); faradaic (involved with electron transfer itself) and non-faradaic (involved a)

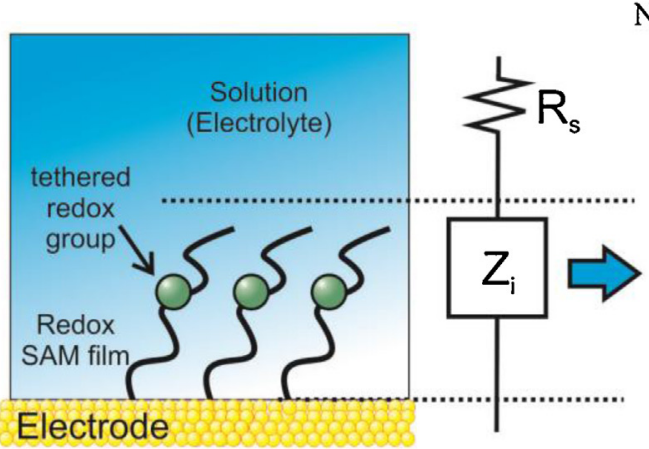

Non-faradaic branch

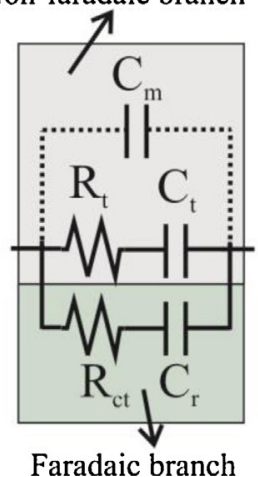

b)

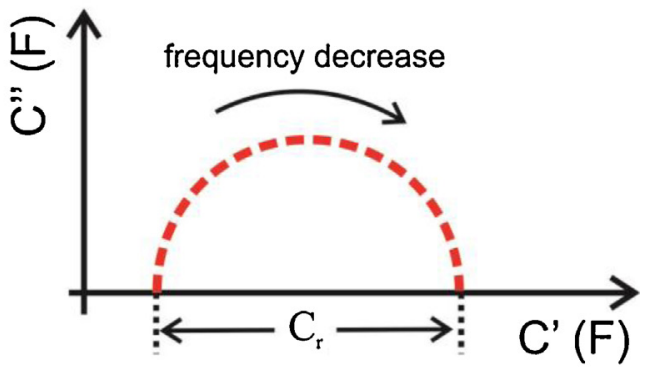

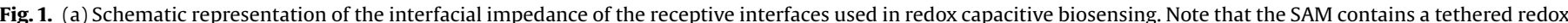

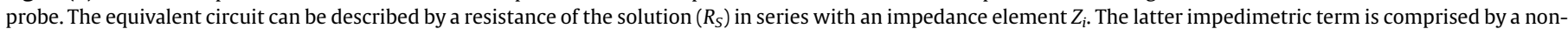

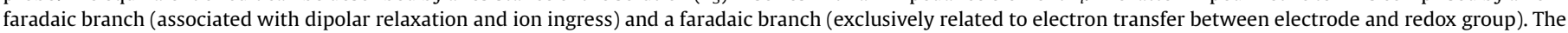

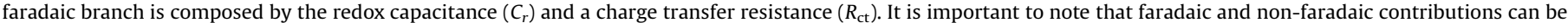

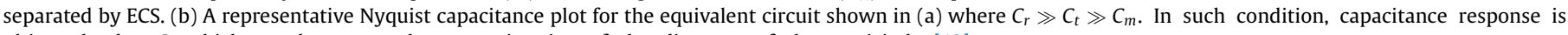
ultimately due $C_{r}$ which can be extract by approximation of the diameter of the semicircle [18]. 


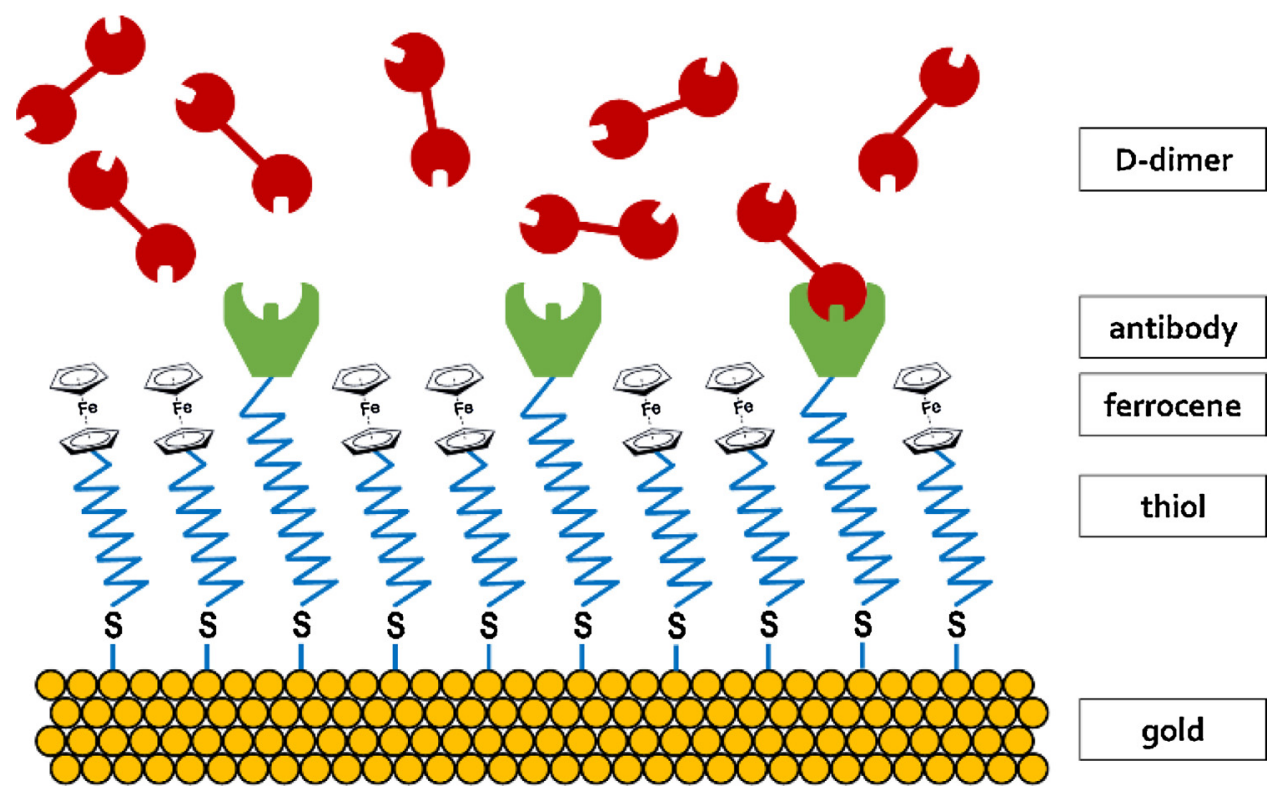

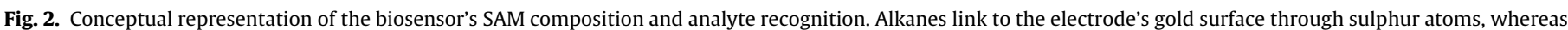

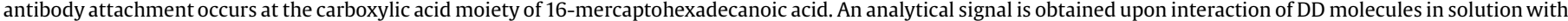
antibodies, which alters the charge transfer between ferrocene [from 11-(ferrocenyl)-undecanethiol] and gold (molecules not drawn to scale).

with dielectric capacitance of the SAM and additionally to the ionic dipolar relaxation contained on it). Depending on the applied potential, the electrochemical behavior of the redox active SAM can be modeled by the non-faradaic circuit only or by both. For instance, in potentials out of the redox activity of the probe (named redox out potential), only contributions related to the non-faradaic branch is observed/measured. The non-faradaic equivalent circuit branch is composed by a parallel combination of a capacitor $\left(C_{m}\right)$ in series with capacitive $\left(C_{t}\right)$ and resistive $\left(R_{t}\right)$ terms, physicalchemically representing the ionic ingress (in the monolayer) that generates an ideal dipole relaxation contributions (i.e. a Debyetype relaxation), as described elsewhere [25]. However, if the energy perturbation is able to promote a redox (electrochemical) activity (redox in potential, where the maximum occurs at the halfwave or formal potential of the redox layer) thus the faradaic contribution either shown in terms of equivalent circuit in Fig. 1a must be considered.

In terms of equivalent circuit, the faradaic branch is composed by a series combination of a resistor $\left(R_{c t}\right)$ and capacitor $\left(C_{r}\right)$, which is related to loss and storage of energy, respectively, in the faradaic process. Experimentally, $C_{r}$ is obtained by an electrochemical capacitance spectroscopy (ECS) approach $[21,23]$, which consist in converting complex impedance into complex capacitance representation. $C_{r}$ is thus easily obtained approximately by the value of the semicircle (and more precisely by its diameter) in the capacitive Nyquist plot as theoretically illustrated in Fig. $1 \mathrm{~b}$ and experimentally in Fig. $3 \mathrm{~b}$.

In this paper, we described the first application of a label-free redox capacitive assay for DD determination, both in buffer (PBS) and neat human serum. This approach demonstrated to be high sensitive and able to detect DD in low concentrations (femtomolar and picomolar), useful for clinical applications. The proposed DD biosensor is based on a bifunctional electroactive self-assembled monolayer (SAM) architecture using two thiol-bearing molecules, a 11-carbon atoms long alkane with ferrocene attached to one end (the electroactive probe) and a 16-carbon carboxylic acid to which antibodies are covalently linked (the anchoring species) as schematized in Fig. 2.
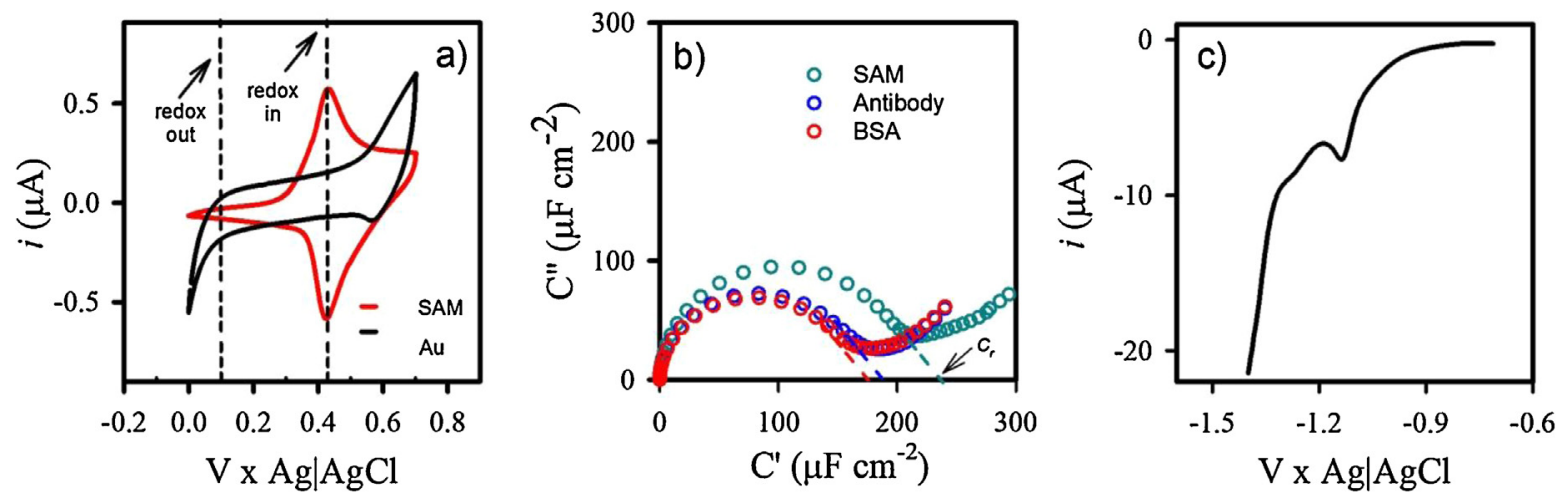

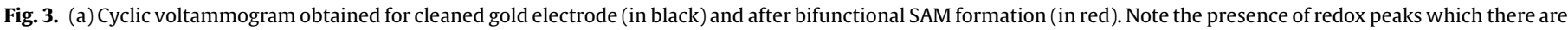

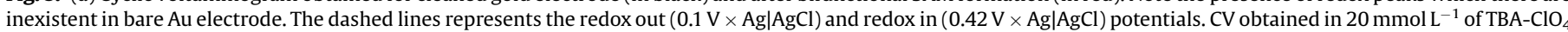

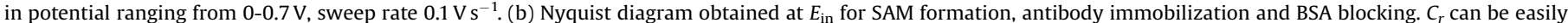

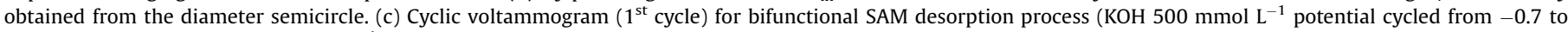
$-1.4 \mathrm{~V} \times \mathrm{Ag} \mid \mathrm{AgCl}$, sweep rate $100 \mathrm{mV} \mathrm{s}^{-1}$ ). 


\section{Experimental}

\subsection{Reagents}

All chemicals and biochemicals were purchased from SigmaAldrich except $\mathrm{H}_{2} \mathrm{SO}_{4}$ which was obtained from Hexis Scientific, and were used without further purification. Solutions of mouseproduced monoclonal anti-fibrinogen antibody $8.2 \mu \mathrm{g} \mathrm{mL}^{-1}$ and bovine serum albumin (BSA) $0.1 \%(\mathrm{~m} / \mathrm{v})$ were either diluted or prepared in phosphate buffered saline (PBS) $\mathrm{pH} 7.4$ with the following composition: $\mathrm{NaCl}, 137 \mathrm{mmol} \mathrm{L}^{-1}$; $\mathrm{KCl}, 2.7 \mathrm{mmol} \mathrm{L}^{-1}$; $\mathrm{Na}_{2} \mathrm{HPO}_{4} \cdot 12 \mathrm{H}_{2} \mathrm{O}, 10 \mathrm{mmol} \mathrm{L}^{-1} ; \mathrm{KH}_{2} \mathrm{PO}_{4}, 1.8 \mathrm{mmol} \mathrm{L} \mathrm{L}^{-1}$. Human plasma DD antigen $1-1,000 \mathrm{ng} \mathrm{mL}^{-1}$ was diluted either in PBS $\mathrm{pH} 7.4$ or neat human serum. Solutions of $\mathrm{NaOH}, 500 \mathrm{mmol} \mathrm{L}^{-1}$; $\mathrm{KOH}, 500 \mathrm{mmol} \mathrm{L}^{-1}$ and $\mathrm{H}_{2} \mathrm{SO}_{4}, 500 \mathrm{mmol} \mathrm{L}^{-1}$ were prepared in Milli-Q water (Simplicity UV ultrapure water system from Millipore with $18.2 \mathrm{M} \Omega \mathrm{cm}$ at $25^{\circ} \mathrm{C}$ ). Mixture solutions of 16 mercaptohexadecanoic acid (16-MHDA) $0.2 \mathrm{mmol} \mathrm{L}^{-1}$ and 11 (ferrocenyl)-undecanethiol (11-F-UDT) $2 \mathrm{mmol} \mathrm{L}^{-1}$ were prepared in anhydrous ethanol. Mixture solutions of $\mathrm{N}$-(3-dimethylaminopropyl)- $N$ '-ethylcarbodiimide (EDC) $200 \mathrm{mmol} \mathrm{L}^{-1}$ and $N$-Hydroxysuccinimide (NHS) $50 \mathrm{mmol} \mathrm{L}^{-1}$ were prepared in Milli-Q water. Solutions of tetrabutylammonium perchlorate $\left(\mathrm{TBA}-\mathrm{ClO}_{4}\right)$ $20 \mathrm{mmol} \mathrm{L}^{-1}$ were prepared in a mixture of acetonitrile:Milli-Q water (20:80).

\subsection{Electrochemical measurements}

All experiments were made at room temperature $\left(25^{\circ} \mathrm{C}\right)$. Cyclic voltammetry (CV) and electrochemical impedance spectroscopy (EIS) measurements were performed using an AUTOLAB potentiostat model PGSTAT302N equipped with a frequency response analysis (FRA) module and the NOVA software from Metrohm. A three-electrode system was used, including the biosensor as working electrode, a platinum mesh as counter electrode and a homemade $\mathrm{Ag} \mid \mathrm{AgCl}$ (saturated $\mathrm{KCl}$ solution). The $\mathrm{DD}$ biosensor was assembled onto a polyether ether ketone (peek) electrode with a $2 \mathrm{~mm}$-diameter polycrystalline gold disk tip (code 6.1204.140) from Metrohm.

\subsection{Surface characterization and Biosensor design}

The biosensor setup involved three major steps which include gold surface preparation, bifunctional SAM formation (i.e. designed SAM for antibody attachment and signal transduction) and antibody attachment. By its turn, surface preparation consisted of another three steps. First, the electrodes were mechanically polished by using $1.0,0.3$ and $0.05 \mu \mathrm{m}$ grain-sized aluminium oxide aqueous suspensions followed by sonication in deionized water for 5 minutes to remove adhered particles. After, a $\mathrm{CV}$ electrochemical desorption step was performed $(\mathrm{NaOH}$ $500 \mathrm{mmol} \mathrm{L}^{-1}$, from -0.7 to $-1.7 \mathrm{~V}, 300$ cycles, $100 \mathrm{mV} \mathrm{s}^{-1}$ ). Next, electrodes were immersed in stirred anhydrous ethanol for 20 minutes to reduce gold oxide [26]. Finally, a CV electrochemical cleaning step was performed $\left(\mathrm{H}_{2} \mathrm{SO}_{4} 500 \mathrm{mmol} \mathrm{L}^{-1}\right.$, from -0.2 to $1.5 \mathrm{~V}, 25$ cycles, $100 \mathrm{mV} \mathrm{s}^{-1}$ ). Electroactive areas were calculated on the basis of cyclic voltammograms from the electrochemical cleaning step by integrating the cathodic peak (details in the Appendix A). The area was used to normalize the capacitance signal.

For bi-functional SAM formation, polished working gold electrodes were immersed in a mixture of 16-MHDA (for antibody attachment) and 11-F-UDT (signal transduction) for 16 hours at $25^{\circ} \mathrm{C}$. After this step, $\mathrm{CV}$ was performed (TBA-ClO ${ }_{4} 20 \mathrm{mmol} \mathrm{L}^{-1}$, from 0.0 to $0.7 \mathrm{~V}, 3$ cycles, $\left.100 \mathrm{mV} \mathrm{s}^{-1}\right)$ to obtain the redox in potential $\left(E_{i n}=\left(E_{o x}+E_{r e d}\right) / 2\right.$, where $E_{o x}$ and $E_{\text {red }}$ are oxidation and reduction potentials, respectively) and 11-F-UDT surface coverage by anodic peak integration (see appendix for details). Lastly, previously to anti-DD antibody attachment, activation of carboxyl groups from 16-MHDA was achieved by immersing SAM-bearing electrodes into a mixture containing EDC/NHS for 30 minutes, and then electrodes were immersed in the antibody solution $(8.2 \mu \mathrm{g}$ $\mathrm{mL}^{-1}$ ) for 1 hour. Electrodes were subsequently immersed in BSA $0.1 \%$ for 30 minutes to block non-specific sites.

DD quantitation and control analyses were accomplished by electrochemical impedance spectroscopy (EIS) using $\mathrm{TBA}^{-\mathrm{ClO}_{4}}$ as supporting electrolyte, modulation frequency varied in 60 steps from 0.01 to $100,000 \mathrm{~Hz}$, peak-to-peak amplitude $10 \mathrm{mV}$, at $E_{\text {in }}$ and $E_{\text {out }}$ potentials experimentally obtained. All measurements were performed in triplicate. The capacitance analysis was done by obtaining $C^{*}(\omega)$ by means of impedance $Z^{*}(\omega)$ using the relationship $C^{*}(\omega)=1 / i \omega Z^{*}(\omega)$, in which $\omega$ is the angular frequency and $i=\sqrt{-1}$ [21]. The asterisk accounts for complex functions. Practically, the real $\left(C^{\prime}\right)$ and imaginary $\left(C^{\prime \prime}\right)$ parts of the complex capacitive function can be directly obtained as a function of real and imaginary terms obtained from the measured complex impedance as $C^{\prime}(\omega)=Z^{\prime \prime} \phi$ and $C^{\prime \prime}(\omega)=Z^{\prime} \phi$, noting that $\phi=1 / \omega|Z|^{2}$, where $|Z|$ accounts for the modulus of the impedance function [21].

Calibration curves were constructed by measuring DD standard solutions from 1 to $1,000 \mathrm{ng} \mathrm{mL}^{-1}$ (five experimental points) in either PBS pH 7.4 or neat human serum. The biosensor was incubated with $50 \mu \mathrm{L}$ of DD standards for 20 minutes prior to measurements. Blank was pure PBS buffer or neat human serum. Negative control analyses, to verify the selectivity of the biosensor response towards $\mathrm{DD}$, were performed by replacing $\mathrm{DD}$ standard with fetuin-A $1,000 \mathrm{ng} \mathrm{mL}^{-1}$ in PBS $\mathrm{pH}$ 7.4. The transduction signal $(S)$ was calculated using the inverse of capacitance, $S=1 / C_{r[D D]}-1 / C_{r[\text { blank }]}$, where $C_{r[D D]}$ is the redox capacitance signal (normalized per area) obtained in a certain DD concentration and $C_{r[\text { blank }]}$ is the response of redox capacitance (normalized per area) with no target in solution (PBS or neat serum without DD). The limits of detection (LOD) and quantification (LOQ) were calculated following IUPAC procedures as three times and ten times the standard deviation of the blank, respectively [27].

$\mathrm{CV}$ electrochemical desorption step was performed $(\mathrm{KOH}$ $500 \mathrm{mmol} \mathrm{L}^{-1}$, potential cycled from -0.7 to $-1.4 \mathrm{~V}$ versus $\mathrm{Ag} \mid \mathrm{AgCl}$ reference electrode, 15 cycles, sweep rate of $100 \mathrm{mV} \mathrm{s}^{-1}$ ) to obtain the bi-functional SAM surface coverage (see Appendix B for details).

\section{Results and Discussion}

Herein, signal transduction is based on electrochemical capacitance, as theoretically defined in the introduction section, sometimes empirically referred as pseudo-capacitance [28] in the electrochemistry literature. Indeed the transducer capacitive signal is measured based on an impedance-derived approach named as electrochemical capacitance spectroscopy (ECS) from where electrochemical capacitance, named in the electroactive monolayer context as redox capacitance $\left(C_{r}\right)$, serve as the sensor signal $[15,16,18,21,24,25,29] . C_{r}$ is a measure of the extension of the reversible charging/discharging of organic films due to charge exchange (electrochemical coupling) between a redox probe tethered to the film and the metallic electrode surface. Alterations in the probe's environment, per example by antigen-antibody binding, affect the monolayer electrochemical energy storage features, and thus $C_{r}$ values.

Electron active SAM functionalization steps were evaluated by $\mathrm{CV}$ (Fig. 3a) and electrochemical impedance spectroscopy (at $E_{i n}=0.42 \mathrm{~V}$, see Appendix B) which in turn was converted to 
complex capacitance, where by using ECS approches $C_{r}$ is generally easily obtained $[16,21,24]$ from the value of the semicircle diameter of the complex capacitive Nyquist diagrams, as shown in Fig. 3b.

Fig. 3a shows CVs performed before and after redox-active SAM formation onto cleaned gold electrode. From these results, it is possible to verify/control the SAM formation due the presence of redox peaks, absent in $\mathrm{CV}$ for bare Au. In addition, a reversible process $\left(i p_{a} / i p_{c} \approx 1\right.$, where $i p_{a}$ and $i p_{c}$ are anodic and cathodic peak current, respectively; and $\Delta E=E_{\mathrm{ox}}-E_{\mathrm{red}} \sim 5 \mathrm{mV}$ ) is observed. From integration of anodic peak (details in Appendix B), the 11-F-UDT surface coverage $\left(\Gamma_{11-F-U D T}\right)$ is of $(2.7 \pm 0.2) \times 10^{-10} \mathrm{~mol} \mathrm{~cm}^{-2}$. From reduction peak (cathodic peak) presented in Fig. $3 \mathrm{c}$ (details in Appendix B) carried out in basic solution ( $\mathrm{KOH} 500 \mathrm{mmol} \mathrm{L}^{-1}$ ), it was obtained a surface coverage for SAM $\left(\Gamma_{S A M}\right)$ of $(5.1 \pm 0.4) \mathrm{x}$ $10^{-10} \mathrm{~mol} \mathrm{~cm}^{-2}$, value found in the same order of magnitude of surface coverage of SAM on gold electrode reported in literature $\left(\Gamma_{\text {SAM }}\right.$ of $7.5 \times 10^{-10} \mathrm{~mol} \mathrm{~cm}^{-2}$ ) [30].

From capacitance analysis of SAM $\left(C_{r} \sim 210 \mu \mathrm{F} \mathrm{cm} \mathrm{cm}^{-2}\right)$ it demonstrates a decrease in $C_{r}$ (from 210 to $180 \mu \mathrm{F} \mathrm{cm}^{-2}$ ) as a consequence of environment perturbation around ferrocenyl groups caused by antibody attachment. Upon addition of bovine serum albumin (BSA), to block non-specific sites on the surface, a slightly decrease in $C_{r}$, to $\sim 170 \mu \mathrm{F} \mathrm{cm} \mathrm{cm}^{-2}$ is still observed. Altogether, these results demonstrate that proper SAM modification was achieved.

On the other hand, from spectroscopic impedance analysis, it is not possible to extract or obtain any information of the biosensor carried out for different DD concentrations (Fig. 4a) at $E_{\text {in }}$ of $0.42 \mathrm{~V}$. Nonetheless, when complex impedance data is converted to complex capacitance domain resulting in a complex capacitive (spectrum) plane (for instance, observed Nyquist capacitive diagram shown in Fig. 4b) it is thus possible to observe the changes caused on the surface mainly by observing as redox capacitance term changes as a function of DD-concentration (Fig. 4b). As previously discussed, ferrocene-gold electron transfer and capacitive charging is altered by DD-antibody interaction. The capacitance response decreased with increasing DD presence, which permitted to infer a linear correlation that could be used for analytical purposes. Furthermore, the capacitance signal is only sensitive to changes on target concentration at $E_{\text {in }}$ potential, as shown in Fig. 4c-d. From the Bode plots, it is possible to infer that both real (Fig. 4c) and imaginary parts of capacitance (Fig. 4d) do not respond in potentials out of the faradaic activity, named as redox out potential ( $E_{\text {out }}$ of $0.1 \mathrm{~V}$ ), but only respond/change as function of target concentration at $E_{\text {in }}$ potential, as expected, since as demonstrated in the introduction section, this corresponds to the potential or energy of the electrode where the faradaic capacitive event takes place (with maximum activity).

The analytical figures of merit were obtained by a calibration curve of standards prepared in phosphate buffered saline (PBS) $\mathrm{pH}$ 7.4 , in triplicate in a concentration range from 1 to $1,000 \mathrm{ng} \mathrm{mL}$ (Fig. 5a).

A good coefficient of determination of the linear regression was verified $\left(r^{2} \geq 0.993\right)$ by fitting the signal transduction $S$ (details in
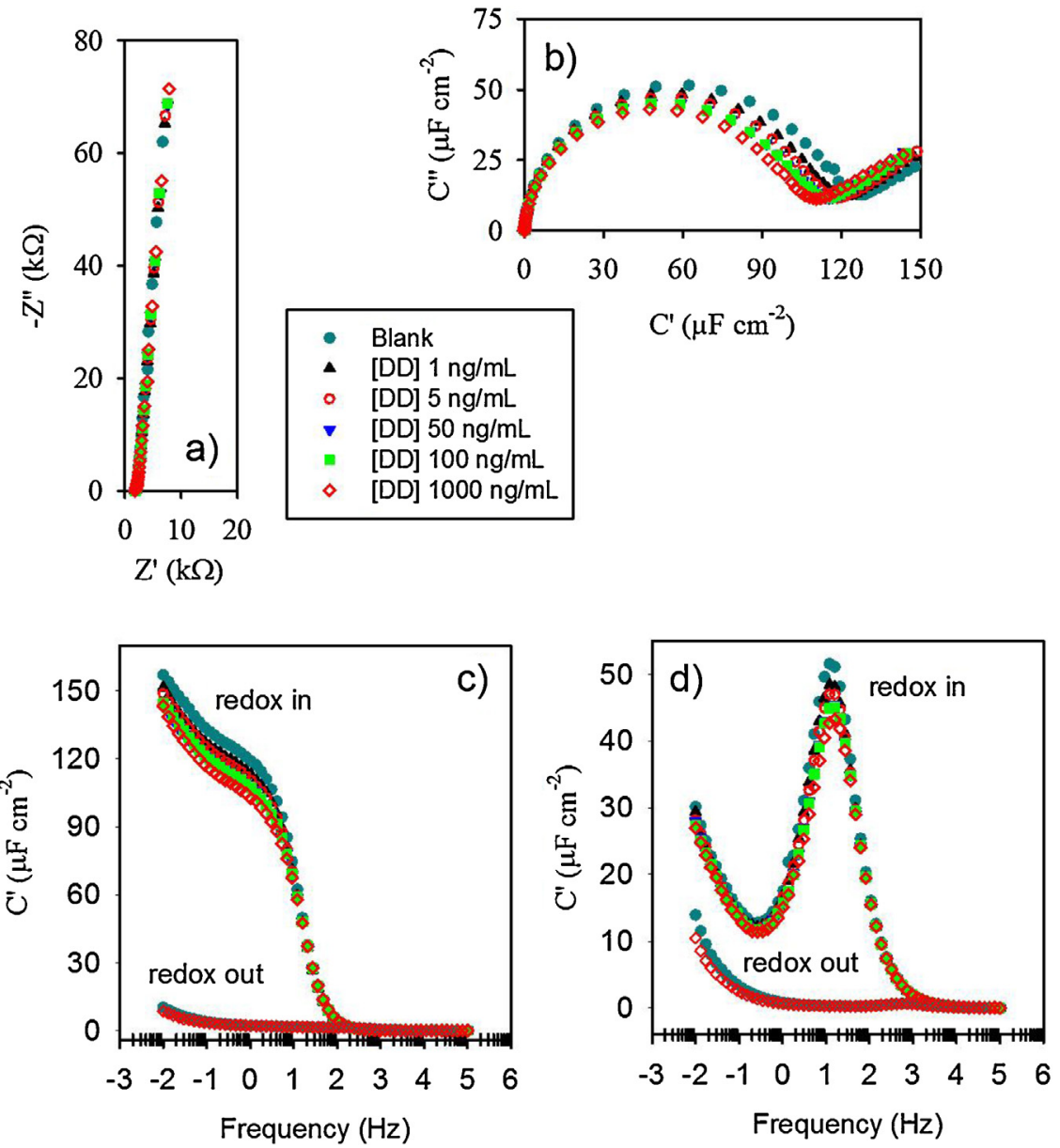

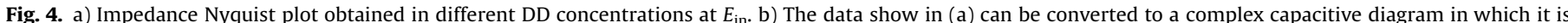

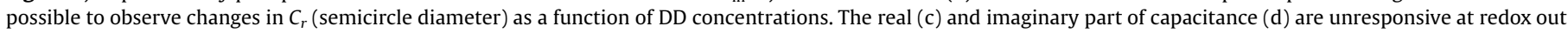
potential $\left(E_{\text {out }}\right)$, but respond sensitively as a function of DD concentrations at redox in potential $\left(E_{\text {in }}\right)$. 
a)

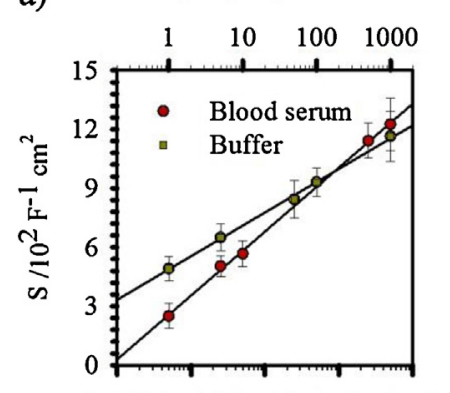

$[\mathrm{DD}] / \mathrm{mol} \mathrm{L}^{-1}$ b)

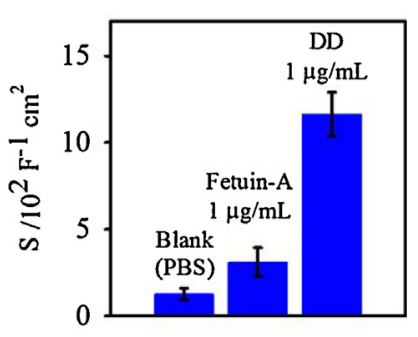

Fig. 5. a) Analytical capacitance curves reporting the inverse of the redox capacitance (signal transduction, $S$ ) for DD determination in a concentration range from 1 to $1,000 \mathrm{ng} \mathrm{mL}^{-1}$ (upper scale) and the corresponding values in molarity (lower scale) obtained both in PBS and neat serum. Plotted data points represent means and standard deviations. b) Selectivity assessment. Redox capacitive signal of $\mathrm{D}$-dimer (DD)-responsive interfaces, in presence of fetuin-A, a nonspecific protein, and the specific target $\mathrm{DD}$, both at a concentration of $1,000 \mathrm{ng} \mathrm{mL} \mathrm{m}^{-1}$.

the Section 2.3) versus the logarithm of DD concentration (Fig. 5a). Very low limits of detection ( $\mathrm{LOD}=10 \mathrm{ng} \mathrm{L}^{-1}$, same as $52 \mathrm{fmol} \mathrm{L}^{-1}$ ) and quantitation ( $\mathrm{LOQ}=130 \mathrm{ng} \mathrm{L}^{-1}$, same as $648 \mathrm{fmol} \mathrm{L}^{-1}$ ) were obtained (unit conversion from mass per litre to molar was done considering a DD molecular weight of $200 \mathrm{kDa}$ [31]), with a relative standard deviation (RSD) of $11 \%$. Negative control analyses, to verify the selectivity of the biosensor response towards $D D$, were performed by replacing DD standard with fetuin-A $1,000 \mathrm{ng} \mathrm{mL}^{-1}$ in PBS $\mathrm{pH} 7.4$, as illustrated by Fig. 5b. By exposing the functionalised SAM surface to fetuin-A, a $\sim 48 \mathrm{kDa}$-blood protein which presents several roles in human physiology [32], a significantly different response, when compared with that obtained with $\mathrm{DD}$, was verified. Indeed, $p$-value $(\alpha$ of 0.05$)$ is much lower than $\alpha, p$ of 0.0004 , which demonstrates/confirms that the average signal obtained for DD statistically differ to those of average signal obtained for fetuin-A at the same concentration (so that validates the analytical response) in a confidence interval of 95\%.

As a proof-of-principle, the biosensor was tested in commercial neat human serum (Fig. 5a). In this case, a good coefficient of determination was also found $\left(\mathrm{r}^{2} \geq 0.999\right)$ with LOD and LOQ in the picomolar range ( 7 and $21 \mathrm{pmol} \mathrm{L}^{-1}$, same as $1.4 \mu \mathrm{gL}^{-1}$ and $4.6 \mu \mathrm{g} \mathrm{L}^{-1}$, respectively) and $R S D$ of $14 \%$. The increase in LOD, LOQ and RSD when compared with the data obtained in PBS are related to biological matrix effects, since this was performed without any kind of sample preparation on the human serum. Nevertheless, the LOD represents better value when compared with others electroanalytical methodologies such as amperometry $\left(25 \mu \mathrm{g} \mathrm{L}^{-1}\right)$ [13] and/or cyclic voltammetry $\left(20 \mu \mathrm{g} \mathrm{L}^{-1}\right)^{12}$, for example (see Table 1 for details on comparisons between different methods). Table 1 demonstrates that the introduced capacitive biosensor is potentially useful to quantify DD in clinical samples.

Indeed, the DD concentration cut-off used in a presumptive PE situation in medicine follows, to a certain extent, the 'thumb rule': age $\times 10 \mathrm{ng} \mathrm{mL}^{-1}$ (e.g. the cut-off for a 65 year old is $\sim 650 \mathrm{ng} \mathrm{mL}^{-1}$ ) [34]. Thus, the studied linear range, 1 to $1,000 \mathrm{ng} \mathrm{mL}^{-1}$, has a valid application for all ages in terms of PE diagnostic. For acute aortic dissection the cut-off has been recently suggested [35] to be $500 \mathrm{ng} \mathrm{mL}^{-1}$. Literature cut-off values for strokes significantly vary and also depend if one talks about acute or chronic ischemia but, in general, values range [4] from 100 to $1,000 \mathrm{ng} \mathrm{mL}^{-1}$. Nevertheless, taking into account all the new studies that point to new diagnostic roles, the low LODs here obtained can be important to make the use of DD significant in other pathologies where it still is not commonly used. Modern medicine is constantly looking for reliable biomarkers of several pathologies, particularly those that are significant and hard to diagnose. The use of DD in the daily hospital routine is handicapped by its mixed value when it is positive, however, its negative predictive value is generally undisputed as meaningful. Quite possibly, DD values have diminished application because of the still time and cost consuming way that they are determined. Perhaps, if they were quantified in a manner as simple as presently glucose is quantified the situation might differ. A recent study showed that, as expected, the DD values are elevated in the post-operative period, however they were also able to show that such rise could be predicted according to the type of surgery (in that case: type I: not entering abdominal cavity $-300 \mathrm{ng} \mathrm{mL}^{-1}$; type II: intra-abdominal -1500 $\mathrm{ng} \mathrm{mL} \mathrm{m}^{-1}$; type III: retroperitoneal/liver surgery $-4000 \mathrm{ng} \mathrm{mL}^{-1}$ ), and they even showed how long these values would take to normalize [36]. This raises the question if DD values could not be used to alter the dose of prophylactic therapy of clotting events, which is typical performed using anticoagulant agents like lowmolecular-weight heparin, in the same way glucose values alter the quantity of insulin prescribed; it should be kept in mind that an excess of anticoagulation can also lead to alarming hemorrhagic events.

\section{Conclusions}

This work describes a simple yet sensitive and specific capacitive label-free without any redox probe in solution biosensor for DD using impedimetric-based measurements. These results create the basis for the development of low-cost, reliable point-ofcare electrochemical chips for the quantitative bedside determination of DD in clinical samples, thus speeding up the diagnosis of many possibly lethal, pathologies like PE.

\section{Acknowledgements}

This work was financially supported by the São Paulo Research Foundation (FAPESP, 2012-22820-7) and National Council for Scientific and Technological Development (CNPq) grants. AS acknowledges CNPq for his Ph.D. studentship (141058/2013-7), SMM acknowledges FAPESP for her research grant (2014/030398) and LMG acknowledges the Portuguese Foundation for Science and

Table 1

Some examples of biosensors for DD determination using different approaches. Unit conversion was done considering a DD molecular weight of 200 kDa [31].

\begin{tabular}{|c|c|c|c|c|}
\hline Approach & Matrix & Concentration range & LOD & Ref. \\
\hline \multirow[t]{2}{*}{ Redox(Electrochemical) capacitance } & Buffer (PBS) & $1-1,000 \mathrm{ng} \mathrm{mL}^{-1}$ & $0.000052 \mathrm{nmol} \mathrm{L}^{-1}\left(0.01 \mu \mathrm{g} \mathrm{L}^{-1}\right)$ & This work \\
\hline & Human serum & $1-1,000 \mathrm{ng} \mathrm{mL}^{-1}$ & $0.007 \mathrm{nmol} \mathrm{L}^{-1}\left(1.4 \mu \mathrm{g} \mathrm{L}^{-1}\right)$ & This work \\
\hline Amperometry & Human serum & $60-1,000 \mathrm{ng} \mathrm{mL}^{-1}$ & $0.12 \mathrm{nmol} \mathrm{L}^{-1}\left(25 \mu \mathrm{g} \mathrm{L}^{-1}\right)$ & [13] \\
\hline Cyclic voltammetry & - & $0.1-100 \mathrm{ng} \mathrm{mL}^{-1}$ & $0.1 \mathrm{nmol} \mathrm{L}^{-1}\left(20 \mu \mathrm{g} \mathrm{L}^{-1}\right)$ & {$[12]$} \\
\hline Surface Acoustic Wave & Buffer (PBS) & $2,000-20,000 \mathrm{ng} \mathrm{mL}^{-1}$ & $<1 \mathrm{nmol} \mathrm{L}^{-1}\left(200 \mu \mathrm{g} \mathrm{L}^{-1}\right)$ & [33] \\
\hline Surface Plasmon Resonance (SPR) & Buffer (PBS) & $300-1,000 \mathrm{ng} \mathrm{mL}^{-1}$ & $1.5 \mathrm{nmol} \mathrm{L}^{-1}\left(300 \mu \mathrm{g} \mathrm{L}^{-1}\right)$ & {$[14]$} \\
\hline Electrochemical Impedance Spectroscopy (EIS) & Buffer (PBS) & $0.5-50 \mathrm{ng} \mathrm{mL}^{-1}$ & $0.0025 \mathrm{nmol} \mathrm{L}^{-1}\left(0.5 \mu \mathrm{g} \mathrm{L}^{-1}\right)$ & {$[14]$} \\
\hline
\end{tabular}


Technology (FCT) for his post-doctoral fellowship (SFRH/BPD/ 76544/2011).

\section{Appendix A. Supplementary data}

Supplementary data associated with this article can be found, in the online version, at http://dx.doi.org/10.1016/j. electacta.2015.09.169.

\section{References}

[1] H. Bounameaux, P. de Moerloose, A. Perrier, G. Reber, Thrombosis and Haemostasis 71 (1994) 1-6.

[2] J. Tsai, S.D. Grosse, A.M. Grant, W. Hooper, H.K. Atrash, Archives of Internal Medicine 172 (2012) 960-961.

[3] J. Antović, Journal of Medical Biochemistry 29 (2010) 282-287.

[4] E. Haapaniemi, T. Tatlisumak, Acta Neurologica Scandinavica 119 (2009) 141150.

[5] A. Wakai, A. Gleeson, D. Winter, Emergency Medicine Journal 20 (2003) 319325.

[6] A. Gutiérrez, J. Sánchez-Payá, P. Marco, M. Pérez-Mateo, Journal of Clinical Gastroenterology 32 (2001) 315-318.

[7] X.-Y. Yang, S. Gao, J. Ding, Y. Chen, X.-S. Zhou, J.-E. Wang, PLoS ONE 9 (2014) e89756.

[8] S.S. Adam, N.S. Key, C.S. Greenberg, Blood 113 (2009) 2878-2887.

[9] M.J. Elms, I.H. Bunce, P.G. Bundesen, D.B. Rylatt, A.J. Webber, P.P. Masci, A.N. Whitaker, American Journal of Clinical Pathology 85 (1986) 360-364.

[10] J.L. Pittet, P. de Moerloose, G. Reber, C. Durand, C. Villard, N. Piga, D. Rolland, S. Comby, G. Dupuy, Clinical Chemistry 42 (1996) 410-415.

[11] M.A. Arugula, A. Simonian, Measurement Science and Technology (2014) 25.

[12] J.S. Rossier, H.H. Girault, Lab on a Chip 1 (2001) 153-157.

[13] M. Gamella, S. Campuzano, F. Conzuelo, A. Julio Reviejo, J.M. Pingarron, Electroanalysis 24 (2012) 2235-2243.

[14] I. Hafaid, A. Gallouz, W. Mohamed Hassen, A. Abdelghani, Z. Sassi, F. Bessueille, N. Jaffrezic-Renault, Journal of Sensors 2009 (2009) 12.
[15] J. Lehr, F.C.B. Fernandes, P.R. Bueno, J.J. Davis, Analytical Chemistry 86 (2014) 2559-2564.

[16] F.C.B. Fernandes, M.S. Góes, J.J. Davis, P.R. Bueno, Biosensors and Bioelectronics 50 (2013) 437-440.

[17] P.R. Bueno, J.J. Davis, Anal. Chem. 86 (2014) 1977-2004.

[18] F.C.B. Fernandes, A. Santos, D.C. Martins, M.S. Góes, P.R. Bueno, Biosensors and Bioelectronics 57 (2014) 96-102.

[19] P.R. Bueno, G.T. Feliciano, J.J. Davis, Physical Chemistry Chemical Physics 17 (2015) 9375-9382.

[20] P.R. Bueno, J.J. Davis, Anal. Chem. 86 (2014) 1337-1341.

[21] P.R. Bueno, G. Mizzon, J.J. Davis, Journal of Physical Chemistry B 116 (2012) $8822-8829$.

[22] A. Santos, J.P. Piccoli, N.A. Santos-Filho, E.M. Cilli, P.R. Bueno, Biosensors and Bioelectronics 68 (2015) 281-287.

[23] A. Santos, J.J. Davis, P.R. Bueno, Journal of Analytical and Bioanalytical Techniques (2014), doi:http://dx.doi.org/10.4172/2155-9872.S7-016 S7:016.

[24] A. Santos, F.C. Carvalho, M.-C. Roque-Barreira, P.R. Bueno, Biosensors and Bioelectronics 62 (2014) 102-105.

[25] M.S. Goes, H. Rahman, J. Ryall, J.J. Davis, P.R. Bueno, Langmuir 28 (2012) 9689 9699.

[26] J. Tkac, J.J. Davis, Journal of Electroanalytical Chemistry 621 (2008) 117-120.

[27] G.L. Long, J.D. Winefordner, Analytical Chemistry 55 (1983) 712-724.

[28] W. Deng, X. Ji, Q. Chen, C.E. Banks, RSC Advances 1 (2011) 1171-1178.

[29] P.R. Bueno, J.J. Davis, Analytical Chemistry 86 (2014) 1337-1341.

[30] J.C. Love, L.A. Estroff, J.K. Kriebel, R.G. Nuzzo, G.M. Whitesides, Chemical Reviews 105 (2005) 1103-1169.

[31] J.B. Walker, M.E. Nesheim, Journal of Biological Chemistry 274 (1999) 5201 5212.

[32] K. Mori, M. Emoto, M. Inaba, Recent Patents on Endocrine, Metabolic \& Immune Drug Discovery 5 (2011) 124-146.

[33] K. Mitsakakis, E. Gizeli, Analytica Chimica Acta 699 (2011) 1-5.

[34] R.A. Douma, G. Le Gal, M. Söhne, M. Righini, P.W. Kamphuisen, A. Perrier, M.J.H. A. Kruip, H. Bounameaux, H.R. Büller, P.M. Roy, BMJ (Online) 340 (2010) 962.

[35] M. Levčík, J. Kettner, A. Jabor, J. Kautzner, Cor et Vasa 55 (2013) e510-e514.

[36] D. Dindo, S. Breitenstein, D. Hahnloser, B. Seifert, S. Yakarisik, L.M. Asmis, M.K Muller, P.A. Clavien, Blood coagulation \& fibrinolysis: an international journal in haemostasis and thrombosis 20 (2009) 347-352. 